\title{
A FENOMENOLOGIA DO ASCO DE AUREL KOLNAI: CONTRIBUIÇÕES PARA O ESCLARECIMENTO FENOMENOLÓGICO DOS AFETOS
}

\author{
Aurel Kolnai's Phenomenology of Disgust: \\ Contributions to the Phenomenological Clarification of Emotions \\ La Fenomenología del Asco de Aurel Kolnai: \\ Contribuciones a la Clarificación Fenomenológica de las Afectos
}

Yuri Amaral de PAUla

TOMMY Akira Goto

\begin{abstract}
Resumo: Historicamente, o movimento fenomenológico esteve marcado por uma grande variedade de investigações dirigidas à elucidação da afetividade e de vivências afetivas particulares. Os primeiros fenomenólogos foram responsáveis por um conjunto amplo de análises sobre as vivências afetivas. Muitas dessas análises foram negligenciadas e continuam sendo pouco discutidas. Compartilhando o mesmo posicionamento conceitual e metodológico desses autores, temos o trabalho de Aurel Kolnai sobre os sentimentos hostis, escritos na década de 1930. Sendo assim, objetivamos reconstituir a análise fenomenológica do asco de Aurel Kolnai presente em seu ensaio denominado "O Asco" de 1929. Para isso, nos baseamos nos critérios e procedimentos metodológicos sistemáticos da pesquisa bibliográfica, partindo da análise do mesmo texto em duas traduções distintas. Com isso, apresentamos um breve resumo da trajetória biográfica e intelectual do autor e os diferentes momentos e análises específicas contidas em seu ensaio, incluindo: a delimitação do asco e seus possíveis pontos de vista de análise, a análise fenomenológica da angústia e do asco, os tipos de asqueriosidade física e moral, sua relação com os sentidos, com a vida e a morte. Concluímos que a descrição fenomenológica dos sentimentos hostis possui utilidade e relevância para o cenário de debates fundamentais ligado ao campo psi.
\end{abstract}

Palavras-chave: Fenomenologia; Afetividade; Afetos; Emoções.

Abstract: Historically, the phenomenological movement was marked by a great variety of investigations directed to the elucidation of affectivity and of particular affective experiences. The first phenomenologists were responsible for a wide set of analyzes on the affective experiences. Many of these analyzes have been neglected and remain little discussed. Sharing the same conceptual and methodological positioning of these authors, we have Aurel Kolnai's work on the hostile feelings written in the 1930s. Thus, we aim to reconstitute Aurel Kolnai's phenomenological analysis of disgust present in his essay entitled "Disgust" from 1929. For this, we base ourselves on the systematic methodological procedures and criteria of the bibliographic research, starting from the analysis of the same text in two different translations. With this, we present a brief summary of the biographical and intellectual trajectory of the author and the different moments and specific analyzes contained in his essay, including: the delimitation of disgust and the possible points of view of analysis, the phenomenological analysis of anxiety and disgust, the kinds of physical and moral disgustingness, their relation to the senses, to life and death. We conclude that the phenomenological description of hostile feelings has utility and relevance for the scenario of fundamental debates related to the psychological related areas.

Keywords: Phenomenology; Affectivity; Affects; Emotions.

Resumen: Históricamente, el movimiento fenomenológico estuvo marcado por una gran variedad de investigaciones dirigidas a la elucidación de la afectividad y de las experiencias afectivas particulares. Los primeros fenomenólogos fueron los responsables de un amplio conjunto de análisis sobre las experiencias afectivas. Muchos de estos análisis han sido descuidados y siguen siendo poco discutidos. Compartiendo el mismo posicionamiento conceptual y metodológico de estos autores, tenemos el trabajo de Aurel Kolnai sobre los sentimientos hostiles escritos en los años treinta. Así, pretendemos reconstituir el análisis fenomenológico del asco de Aurel Kolnai, presente en su ensayo titulado "El Asco" de 1929. Para ello, nos basamos en los procedimientos y criterios metodológicos sistemáticos de la investigación bibliográfica, a partir del análisis del mismo texto en dos traducciones diferentes. Con esto presentamos un breve resumen de la trayectoria biográfica e intelectual del autor y de los diferentes momentos y análisis específicos contenidos en su ensayo, entre los que se incluyen: la delimitación del asco y los posibles puntos de vista del análisis, el análisis fenomenológico de la angustia y el asco, los tipos de asquerosidad física y moral, su relación con los sentidos, con la vida y con la muerte. Concluimos que la descripción fenomenológica de los sentimientos hostiles tiene utilidad y relevancia para el escenario de debates fundamentales relacionados con las áreas psicológicas.

Palabras-clave: Fenomenología; Afectividad; Afectos; Emociones. 


\section{Introdução}

Desde seu surgimento ao desdobramento posterior, o movimento fenomenológico esteve marcado por uma grande variedade de investigações dirigidas à elucidação da afetividade e de vivências afetivas particulares. Historicamente, isso é possível observar desde as obras fundacionais de Edmund Husserl (1859-1938), com os dois volumes de suas Investigações Lógicas de 1900 e 1901, em que se destaca o §15 da Quinta investigação, sobre os sentimentos (Ferran, 2015; Goto, Telles \& Paula, 2016), ou pelo estudo de Alexander Pfänder (1870-1941), denominado Fenomenologia da vontade de 1900 (Ferran, 2015). Nesse cenário, temos também os trabalhos posteriores como a fundamentação ontológica de base existencial das tonalidades afetivas na obra de Martin Heidegger (18891976), bem como os primeiros trabalhos de Jean-Paul Sartre (1905-1980) sobre as emoções, escritos no interesse de formular uma psicologia fenomenológica (Calhoun \& Solomon, 1996; Casanova, 2010; Sartre, 2008).

Entretanto, é impar destacar os trabalhos de toda uma variedade de autores do "primeiro período do movimento fenomenológico", cuja contribuição original para a descrição das experiências concretas inclui uma ampla e variada gama de análises complexas e detalhadas a respeito da vida afetiva, que, por múltiplas razões, acabaram sendo largamente negligenciadas e ofuscadas, de modo que, por consequência disso, continuam sendo pouco discutidas, com raras exceções, em publicações referentes ao campo da fenomenologia (Ferran, 2015, p. 329). Assim, entre esses estudiosos considerados "largamente desconhecidos, apesar de suas detalhadas análises da vida afetiva efetuadas nesse período", escritas entre 1905 e 1925, cujos trabalhos defendiam todos, ao seu próprio modo, a "primordialidade da esfera afetiva e seu domínio próprio de evidência”, temos: Alexander Pfänder (1870-1941), Max Scheler (1874-1928), Edith Stein (1891-1942), Moritz Geiger (1880-1937), Carl Stumpf (1848-1936), Willy Hass (1883-1956) e Gerda Walther (1897-1977) (Ferran, 2015, p. 330-331).

Esses "primeiros fenomenológos" (early phenomenologists) se constituíram como um "grupo heterogêneo de pensadores ativos durante esse primeiro período do movimento fenomenológico", que compartilharam, além de um período histórico e contexto geográfico comum em torno do "mestre" Husserl: 1) uma atitude metodológica, a saber, a redução eidética, concebida como via realista, inspirada na fenomenologia de Husserl com as suas Investigações Lógicas, 2) a consideração sobre o caráter essencialmente intencional da consciência, incluindo as próprias vivências afetivas, 3) a concepção e análise da fundamentação das vivências afetivas, consideradas como atos não objetivantes, sobre atos objetivantes, 4) a concepção a respeito da relevância do estudo das vivências afetivas para a fundamentação da ética por sua correlação essencial com os valores, isto é, com tudo aquilo que se mostra como valioso em nossa experiência. Cabe destacar ainda que essas três últimas posições foram herdadas e revisadas por Husserl a partir do trabalho originário de seu mestre e amigo, o filósofo psicologista, Franz Brentano (1838-1917) (Ferran, 2013, 2015).

Ainda, nesse contexto de coesão metodológica e temática, destacam-se também o trabalho de outros três autores, sendo eles Dietrich von Hildebrand (1889-1977), José Ortega y Gasset (1883-1955) e Aurel Kolnai (1900-1973), que, embora tenham desenvolvido e publicado suas próprias investigações fenomenológicas em momento posterior à dissolução dessa formação original do grupo de autores do primeiro período do movimento fenomenológico, também podem ser considerados como parte desse grupo por terem produzido análises sobre a esfera afetiva na mesma linha, compartilhado dos mesmos posicionamentos citados (Ferran, 2015).

Com isso, diante do vasto panorama de contribuições clássicas de autores da fenomenologia capazes de nos oferecer compreensões sobre os múltiplos aspectos das chamadas vivências afetivas e considerando a possibilidade de minimizar em parte esta lacuna de divulgação e discussão, elegemos nesse estudo nos concentrar na contribuição de Aurel Kolnai, cuja obra, significativamente desconhecida no cenário brasileiro, contempla uma peculiar atenção em relação aos chamados "sentimentos hostis”, isto é, às manifestações afetivas de ordem defensiva que nos mostram a possibilidade cortar nossos laços positivos com o mundo e seus objetos, tais como o asco, a soberba, o ódio, o medo etc. (Ferran, 2013). O estudo sobre essa contribuição pontual também se justifica pela consideração de estudiosos especializados neste campo a respeito da validade e rigor que as respectivas análises descritivas possuem no interior do debate contemporâneo acerca dos afetos (Ferran, 2015; Quepons, 2014), também em função do possível esclarecimento para o campo da investigação da psicologia acerca dos processos psicológicos básicos (Goto, Telles \& Paula, 2016).

Desse modo, o presente artigo tem por objetivo reconstituir a análise fenomenológica do asco de Aurel Kolnai presente em seu ensaio denominado O Asco, publicado originalmente em 1929, explicitando, em linhas gerais, a sua estrutura de exposição bem como os distintos momentos a partir dos quais o referido autor discute no texto os aspectos essenciais referentes às vivências afetivas por ele analisadas. Contudo, neste artigo, deixaremos de lado por hora a exposição e discussão da última parte do ensaio dedicada à tematização ética do asco, porque esta parte escapa momentaneamente ao nosso interesse ligado ao esclarecimento dos aspectos fenomenológico-psicológicos do asco. Assim, na efetivação do nosso percurso reconstrutivo, nos baseamos nos critérios e procedimentos metodológicos sistemáticos da pesquisa bibliográfica, tal como definida por Lima e Mioto (2007) e Salvador (1986), de modo que nos propomos a reconstituir estritamente as ideias presentes no texto a partir da análise do mesmo 
em duas traduções publicadas, nos idiomas inglês (Kolnai, 2004) e espanhol (Kolnai, 2013).

\section{Breve trajetória biográfica e intelectual de Aurel Kolnai}

Nascido em 1900 em Budapeste, à época parte do Império Austro-Húngaro, no seio de uma família judia secular e acomodada, Aurel Thomas Stein ao completar dezoito anos mudou seu sobrenome para Kolnai com objetivo de obscurecer a sua origem judia, a fim de evitar a possibilidade de se tornar alvo ideológico no estado húngaro de outrora. Com esse acontecimento, sinaliza, segundo Ferran (2013, p. 07), “uma constante ao longo de sua vida: o vínculo íntimo entre seu devir vital e intelectual e os acontecimentos históricos mais agitados do século passado”. Tendo vivido as duas Guerras Mundiais, morado em vários países europeus, antes de se emigrar para os Estados Unidos da América, e, posteriormente, retornado à Europa em meados dos anos 50, sua vida e trabalho intelectual estiveram decisivamente marcadas pelos acontecimentos de seu tempo. Sua extensa obra, aparentemente heterogênea, à primeira vista, permite denotar como "fio condutor o interesse do autor por questões morais e sua preocupação pelo acontecer sociopolítico do século XX”, bem como sua capacidade de se movimentar por "diferentes estilos e correntes filosóficas, de escrever em vários idiomas - húngaro, alemão, inglês, francês e espanhol - e de sobreviver a vários ecossistemas intelectuais, sem perder a agudeza intelectual e a originalidade própria dos grandes pensadores”. Assim, temos que Kolnai expressou em sua obra uma evolução notável que se subdivide em quatro etapas principais.

A primeira etapa de sua trajetória intelectual foi marcada pela psicanálise quando, aos 19 anos, esteve próximo de figuras importantes do movimento psicanalítico como Sándor Ferenczi, na Hungría, e com Otto Rank e Sigmund Freud, em Viena. Interessado particularmente por suas implicações culturais, escreveu uma série de textos que apresentavam considerações sociológicas desde a psicanálise. Contudo, em função de um paulatino e definitivo desinvestimento em relação à psicanálise, em grande parte em função das descobertas seguintes ao longo de sua continuada formação intelectual, denota Ferran (2013, p. 9), o autor encontrou "um marco conceitual muito mais adequado para o desenvolvimento de seus interesses intelectuais", que caracterizou a segunda etapa de seu pensamento interessado pelo estudo e desenvolvimento de trabalhos ligados à fenomenologia.

Motivado pelo mesmo projeto que os primeiros fenomenólogos (embora, como vimos, não pertença a esse grupo por razões de tempo e geografia), dirigido ao esclarecimento de tipo realista a respeito dos problemas filosóficos ligados à ética dos valores, a partir do estudo dos atos afetivos, se apropriou do mesmo embasamento ligado à atitude fenomenológica ou método, considerado no sentido amplo, da "redução eidética", concebida enquanto procedimento de "analisar um fenômeno da experiência, identificando suas características essenciais frente a fenômenos similares, descrevendo-os e estudando-os até chegar a captar os momentos constitutivos do mesmo" (Ferran, 2013, p. 09), possibilitando, assim, "elaborar taxonomias e tipologias" que correspondessem rigorosamente ao modo de se manifestar à consciência dos fenômenos da esfera afetiva, analisados "até suas últimas consequências” (p. 13). Então, no marco desse pertencimento à corrente filosófica da fenomenologia, "em torno da década de 30, escreve Kolnai uma série de ensaios sobre os sentimentos hostis" nos quais sistematicamente trata os temas do asco, soberba e ódio.

Com a mudança da situação sociopolítica na Europa durante os anos 30, como afirma Ferran (2013), Kolnai transita para outra fase de seu pensamento precipitada pela "sombra do fascismo" especialmente sentida "na Áustria, onde o partido nacionalsocialista [nazista] obtém seus primeiros êxitos" (p. 14). Dessa maneira, "sob a influência de pensadores sociais e políticos, ante a iminente Segunda Guerra Mundial e a conseguinte emigração à América do Norte” (p. 08), seguindo a tendência de sua precoce compreensão a respeito da seriedade do momento sociopolítico em que vivia, passa o autor a se dedicar à escrita de uma série de artigos periodísticos e de livros voltados à denúncia, crítica e problematização das questões políticas, sociológicas e culturais de seu tempo.

Por fim, tendo-se mudado para o Reino Unido, encontrando um novo "ambiente dominado fortemente pela filosofia analítica”, Kolnai mais uma vez "deixa que sua obra se imbua do espírito do tempo que lhe tem tocado viver". No entanto, "apesar de que introduza elementos próprios da nova corrente, não pode ser considerado como um representante do novo movimento", mas que, segundo ele mesmo, permaneceu até o fim de sua carreira como discípulo do movimento fenomenológico que declarou ter marcado todo seu trabalho de modo significativo e contínuo (Ferran, 2013, p. 16-17).

Kolnai falece em 1973, deixando um conjunto amplo de obras publicadas em vida e também póstumas, sendo estas em grande parte organizadas e publicadas por seus colegas londrinos, encarregados da difusão de seus textos. Entre elas, destacamos as principais: os ensaios psicanalíticos denominados "A significação da psicanálise para a sociologia" (Die Bedeutung der Psychoanalyse für die Soziologie) e "Psicologia do anarcocomunismo" (Psychologie des Anarcho-Kommunismus); o livro de 1920 denominado "Psicanálise e Sociologia. Sobre a psicologia das massas e a sociedade" (Psychoanalyse und Soziologie. Zur Psychologie von Masse und Gesellschaft); o texto que marca a transição da psicanálise para a fenomenologia publicado na revista Imago em 1925, denominado "Crítica e elogio da teoria freudiana da libido de Max Scheler" 
(Max Schelers Kritik und Würdigung der Freudschen Libidolehre); seu estudo de doutorado "O valor ético e a realidade" (Der ethische Wert und die Wirklichkeit); seu livro sobre o tema da sexualidade do ponto de vista do catolicismo, ética e poder político de 1930 "Ética sexual: sentido e fundamentos da moral sexual" (Sexualethik: Sinn und Grundlagen der Geschlechtermoral), seus ensaios da década de 1930 sobre os sentimentos hostis, organizados na obra "Asco, soberba, ódio. A fenomenologia dos sentimentos hostis" (Ekel, Hochmut, Haß. Zur Phänomenologie feinlicher Gefühle); seu livro publicado contra o nacional socialismo, de 1938, que o lançou para a fama, denominado "A Guerra contra o Ocidente" (The War against the West), entre outros textos sociopolíticos como "Os Três Cavaleiros do Apocalipse: Comunismo, Nazismo e Democracia Progressiva” (The Tree Riders of Apocalypse: Communism, Naziism and Progressive Democracy); por fim, o texto póstumo "Os modos de aversão comuns: Medo, Asco e Ódio" (The Standard Modes of Aversion: Fear, Disgust, and Hatred), que retomam as teses sobre os sentimentos hostis formuladas durante os anos trinta (Ferran, 2013, p. 08-17).

\section{A fenomenologia do asco de Aurel Kolnai}

Como breve contextualização do ensaio O Asco (Der Ekel) de Kolnai (2013), temos que foi escrito em 1927 e publicado no décimo volume do Anuário Jahrbuch für Philosophie und phänomenologische Forschung, em 1929, e atribui-se que tenha despertado estranhamento e curiosidade em Husserl devido a sua temática. Precedendo ao texto de Kolnai (2013) encontramos uma nota publicada dos editores em que apresentam este trabalho como exemplo exitoso da chamada corrente fenomenológica, inaugurada por Edmund Husserl com a publicação de sua obra Investigações Lógicas de 1900 e 1901, em produzir descrições a respeito dos sentimentos humanos. Ainda, consideram esses editores comentadores que, por meio da análise fenomenológica do asco apresentada pelo referido autor, ficaria indicado "de que maneira a fenomenologia descobre valores e leis objetivas determináveis cientificamente no que, como os sentimentos, parecia vago, flutuante, subjetivo, caprichoso", dessa forma, demonstrando sua capacidade de explicitar rigorosamente algo "tão indescritível a primeira vista” (p. 33).

Kolnai (2013, p. 33-34) introduz em seu ensaio o asco como fenômeno relativamente pouco estudado em contraste com “interesse psicológico e metafísico” por outros afetos como ódio e angústia. Com isso, destaca que o problema do asco "oferece à investigação um território completamente novo, ainda que constitua uma parte essencial, diária e muito acusada de nossa vida sentimental”. Descaracterizado por vezes com definições que não se atentam ao conteúdo intuitivo particular desta vivência, denota o autor que o asco "possui uma qualidade de tal maneira própria, unívoca e característica, e, por sua vez, tão difícil de aclarar por meio de conceitos”.

Por essa razão, fica justificada para Kolnai (2013, p. 34) a adequação de uma "verdadeira investigação fenomenológica”, considerada capaz de delimitar a especificidade acentuada do asco frente a outras vivências bem como a ampla extensão de seus objetos próprios. Assim, antecipa uma distinção que irá descrever ao longo de seu ensaio entre a esfera física (ou psicológica) e a moral (ou espiritual) em que "podemos encontrar, com leis diferenciais de matiz, o mesmo asco", de modo que a qualidade de asco correlacionada, o caráter de ser "asqueroso", propriamente dito, pode ser encontrado em ambas as esferas de modo "quase igual", em função de uma identidade essencial de conteúdo. Deste modo, compreende o autor que existem traços dominantes do asco que se mantêm, apesar da distinção existente entre as esferas particulares nas quais este se expressa, bem como diante da considerável amplitude de objetos próprios capazes de suscitá-lo e em relação aos quais se encontra a cada momento referido.

Dessa forma, considera o autor que para atingir o objetivo de "delimitar rigorosamente o aspecto puramente fenomenológico do asco" sua pesquisa deve guiar-se pelo propósito metodológico de buscar captar, intuitiva e compreensivelmente, "a essência, a significação, a intenção do asco e, por assim dizer, as leis que unem o mundo de seus objetos". Ainda, antecipa que buscará concretizar este objetivo a partir da comparação com outras vivências afetivas como, em especial, a angústia e que irá discutir, embora brevemente, "a importância e significação do asco na ética” (Kolnai, 2013, p. 34).

\subsection{A delimitação do asco e seus pontos de vista de análise}

Kolnai inicia a primeira seção do ensaio voltada à delimitação do asco apresentando-o como vivência afetiva pertencente à categoria das chamadas "reações de defesa" ou, segundo o autor, dito de modo mais delicado, dos "sentimentos de repulsa" (Kolnai, 2013, p. 34). Ou ainda, em acordo com a expressão alternativa encontrada na tradução inglesa deste segundo termo (Kolnai, 2004, p. 30), pertence aos “modos de aversão" (modes of aversion). Dessa maneira, destacando outros afetos que fazem parte desta categoria ao lado do asco, como desprazer, desgosto, ódio, horror, angústia, medo etc., o autor nos apresenta os "múltiplos pontos de vista" a partir dos quais "a investigação das diferenças entre uns e outros pode ser acometida”. Assim, considera ao todo, sete pontos de vista, "sem negar que entre alguns existe uma íntima relação e que tampouco são os únicos possíveis" (Kolnai, 2013, p. 34).

Começando pelo primeiro ponto de vista denominado como "esfera dos objetos" (intencionais), expõe o autor que o asco nunca se relaciona, com exceção da 
sujeira, "com o inorgânico, o desprovido de vida”. Essa delimitação, nos descreve, não está presente como condição em outras vivências tais como na angústia e no desagrado. Considerando o segundo ponto de vista, referente à "intencionalidade", interpretada em termos de uma variação gradativa em escala qualitativa relativa à presença bem definida até outra mais indefinida de um objeto presente à vivência, denota que tal presença bem delimitada de objeto "ocupa o primeiro plano no ódio e no desprezo; se marca menos no asco; descende ao mínimo no mal humor e desaparece na incomodidade". Ainda sob esse ponto de vista ou categoria de análise, descreve também: "uma maior flutuação do grau de intencionalidade encontramos na pena (uma 'autêntica' falta de 'intencionalidade' é possível para o simples desprazer) e, estruturada de maneira muito distinta, na angústia” (Kolnai, 2013, p. 35, grifos do autor).

O terceiro ponto de vista de análise, chamado "caráter de "estado" ou, como encontrado no texto da tradução inglesa, "condition [Zuständlichkeit] of the subject" (Kolnai, 2004, p. 31), remete ao traço gradativo ligado às vivências afetivas enquanto "modalidade de toda a disposição atual do ânimo da pessoa". Em outros termos, com esta categoria de análise busca determinar o grau em que as vivências afetivas envolvem a totalidade da disposição de ânimo (enquanto estado afetivo global) da pessoa quando vividas de modo atual. Assim, sob esse ponto de vista, analisa que "o ódio é mais 'estado' que o desprezo, o asco mais que o ódio, a cólera mais que o asco", sendo que "a cólera é, por assim dizer, plenamente 'estado'; não menos que o mau humor" (Kolnai, 2013, p. 35 , grifos do autor).

Em seguida, realiza a análise do grau de "imediatidade ou primordialidade", que remete ao traço de maior dependência em relação à impressão sensível e, em relação inversa, uma menor relação com a apercepção da situação objetiva como estado de coisas assim como menor determinação pelo conhecimento prévio e atitudes estimativas pré-estabelecidas da pessoa. Dessa maneira, estabelece que o asco, assim como mais intencional, é mais imediato e sensivelmente determinado do que a cólera, assim como em relação à aversão, sendo "que esta, por essência, supõe, em grau maior, uma base consciente e supõe mais do que (...) [o asco] uma fundamentação consciente, uma aquisição deliberada (aversão à moscas como portadoras de enfermidades)", dependendo de conhecimento adicional sobre o objeto, traço menos determinante no asco (Kolnai, 2013, p. 36, grifos do autor).

Apresenta o ponto de vista relativo à "independência", que, em sua perspectiva, caracteriza a "oposição ou resistência a fundar-se em outras reações mais amplas de defesa", isto é, compreende o traço de certas vivências afetivas de serem independentes, no sentido de não se mostrarem acompanhadas de outras, sejam associadas, fundadas ou contidas na mesma. Com isso apresenta que a angústia é mais independente do que o asco, pois "o asco, sem ter que conter a angústia, alude de alguma maneira à angústia, e, se bem erroneamente - ainda que não por completo sem fundamento -, se o considera às vezes como subespécie da angústia”. Considerando este ponto de vista, apresenta também que "o desprezo, pelo menos na maior parte de suas formas, assinala indiscutivelmente o asco" (Kolnai, 2013, p. 36, grifos do autor).

Na sequência, com respeito ao ponto de vista da " $\mathrm{Cor}$ poralidade", denota que o asco está mais ligado ao corpo do que o ódio e a cólera. Ainda, sobre esta última, indica que "apesar da vivacidade dos fenômenos corporais que acompanham a cólera, intervêm com papel mais essencial no asco as impressões sensíveis e o presságio de uma reação corporal (vômito), muito mais específica e concreta" que os gestos expressivos da cólera como o golpear e arremessar algo. Contudo, alerta que o asco não deve ser confundido com a própria náusea. E, denota que a angústia está mais ligada ao corpo do que o asco por conter uma intrínseca direcionalidade intencional "ao próprio corpo como tal, a sua integridade" (Kolnai, 2013, p. 36, grifos do autor).

Por fim, temos o último ponto de vista destacado que diz respeito ao "caráter de resposta", que remete ao traço reativo de certas vivências afetivas que se caracterizam como "verdadeiras 'reações', respostas adequadas, adaptadas a impressões perturbadoras", tais como o caso do asco e da angústia. Assim, tais vivências se mostram em contraste com outras marcadas pelo traço de maior "espontaneidade", oposto ao sentido do "caráter de resposta", como o ódio e o mal estar, que, segundo o autor, embora tenham graus de intencionalidade distintos - o primeiro "altamente intencional" e o segundo "apenas (...) intencional" -, demonstram ambos uma maior espontaneidade: "um buscando, escolhendo, perseguindo [seu objeto]; o outro, por assim dizer, crescendo, potencializando-se". Dessa forma, em referência aos exemplos apresentados, considera ainda o autor que enquanto o asqueroso e o temível, como qualidade intencional objetiva do asco e da angústia, respectivamente, as suscitam como reações específicas ao valor assim manifesto, o ódio flui, de forma mais imediata e direta, em direção ao odioso - que, segundo o autor, tem algumas de suas objetivações possíveis na forma do inimigo, do mal ou mesmo do estranho -, caracterizando assim o sentido de maior espontaneidade do ódio em contraposição à reatividade do asco e da angústia (Kolnai, 2013, p. 37, grifos do autor).

\subsection{O contraste fenonomenológico do asco e da an- gústia}

Mostra-se relevante a essa altura explicitarmos a concepção de "angústia” (Angst) utilizada por Kolnai (2013). Para o filósofo húngaro, trata-se a angústia (assim como o asco) de uma vivência intencional, ou seja, que contém 
essencialmente uma referência objetiva em relação a qual a vivência de sentimento está dirigida, ainda quando na forma de um objeto indeterminado, ou seja, "inclusive quando às vezes se utiliza essa noção para referir-se a um sentimento imotivado e em aparência sem relação com nada” (Quepons, 2014, p. 180-181), “isto não muda o caráter essencial de toda angústia: segue sendo angústia de ‘algo' que produz angústia” (Kolnai, 2013, p. 37). Dessa forma, segundo o autor:

A denominação “angústia” não deve aqui indicar uma rigorosa diferenciação entre medo e angústia, excluindo, portanto, de nosso estudo o medo ante os objetos realmente perigosos. É certo que sob o nome de "angústia”, em sentido estrito, pode compreender-se o estado de medo imotivado, que não se relaciona estreitamente com nenhum objeto determinado e que flutua mais ou menos livremente; mas usamos a palavra em seu amplo sentido, e a preferimos ao termo "medo", para conservar a representação do sentimento redundante, pleno, de medo (pavor), a diferença do medo como simples "preocupação" ante a possibilidade de um fato indesejável ou a presunção de um perigo (timor). Em geral, nos referimos à angústia "normal” objetiva, ainda que seja desproporcional com o objeto - "ante algo". (Kolnai, 2013, p. 41)

Com isso, a concepção de angústia de Kolnai (2013) se particulariza - "um pouco à contracorrente do exemplo predileto de Heidegger” (Quepons, 2014, p. 180) - por considerar os referidos modos de presentificação como parte de uma mesma vivência afetiva: seja como vivência com objeto intencional explícito de modo consciente ou no modo de manifestação afetiva "sem motivo consciente" (Kolnai, 2013, p. 37) e "que não se relaciona estreitamente com nenhum objeto determinado e que flutua mais ou menos livremente" (p. 41). Tendo isso em consideração, adentramos na exposição da segunda seção do ensaio sobre o asco em que o autor realiza uma detalhada elucidação da essência do asco a partir de sua peculiar comparação com a angústia considerada como fenômeno intencional, explicitando a especificidade de cada afeto a partir da descrição de seu modo intencional.

Sendo assim, em relação ao modo intencional da angústia, descreve Kolnai (2013, p. 41) que é dupla, ou seja, "se refere, simultaneamente, a dois objetos completamente independentes: o objeto que produz a angústia e a pessoa ou sujeito que a sofre”. Esclarece assim que na angústia se vive em face de uma "ameaça de perigo, à ideia dela”, mas que não se dá de modo deslocado e sem referência ao eu, "mas, evidendentemente, somente em atenção a mim mesmo, a minha pessoa”. Entrementes, essa referência a si mesmo não impede que se viva também angústia ou medo a partir da ameaça a algo distinto da própria pessoa, mas que está de alguma maneira relacionado a ela. Sobre isto, considera:
Que se trate de algo próximo a minha existência, meu interesse ou saúde de minha alma ou de um interesse alheio e que, mesmo assim, me seja caro, é coisa completamente indiferente para essa propriedade da intenção de dirigir-se a algo; enquanto que, sem dúvida, não é indiferente que o estado mais típico de medo seja o egoísta, o que se refere a si mesmo (uno mismo); enquanto que o medo por uma pessoa querida, por um eu alheio, representa já uma espécie mais complicada de sentimento. (Kolnai, 2013, p. 41)

Dessa maneira, compreende Kolnai (2013, p. 42) que o conceito de angústia (ou medo), "em todos os casos, alude ao próprio bem ou ao próprio dano”, sendo, portanto, "inseparável do conceito de ameaça, perigo, necessidade de salvar-se ou de socorro", ou seja, indica o interesse de alcançar alguma forma de proteção frente ao que põe em risco, pelo teor ameaçador ou perigoso presente no seu objeto, o eu ameaçado. Ainda, dada essa essencial correlação da experiência de angústia com algo que se mostra como ameaça ou perigo, denota o filósofo um componente potencial que dela emerge: "a fuga ante um perigo" que contém uma "intenção rigorosamente teleológica”, sendo "o membro final ou conclusão, a descarga impulsiva, impetuosa, da angústia”.

Kolnai (2013, p. 42) indica também que "se nos sabemos em completa segurança ante algo que por si mesmo é perigoso, ameaçador, então a angústia descende ao plano de um leve estremecimento (que já não é, em verdade, nem 'angústia débil')”. Dessa forma, aponta a possibilidade de se dominar (até certo ponto) a estrita reatividade contida como elemento instintivo na angústia ou medo diante de alguma objetividade real ou potencialmente perigosa em função da "consciência da situação", isto é, da "convicção real de que nesta ocasião tem desaparecido todo perigo". Experiencialmente, exemplifica Kolnai (2013, p. 42), isto "se adverte na maneira de comportar-se o homem - quase sempre isenta de todo rastro de angústia - ante às feras enjauladas”.

Quanto à dupla intenção da angústia em se dirigir ao objeto que a suscita e ao eu que se vê ameaçado pelo objeto, considera o autor que essa está presente “ainda em certos casos limites pouco claros; por exemplo: quando eu tenho angústia ‘de mim mesmo’”. Neste caso, reflete o autor que estamos diante de uma patentização da "cisão intencional do próprio eu", na qual o "eu material, real, eficiente" se divide em dois, "no qual a parte voluntária, que está acima, ancorada no próprio interesse moral ou material, se vê ameaçada pela outra; por exemplo, pela impulsiva e passional”. Caso semelhante desta "cisão intencional do próprio eu" acontece, também, de acordo com Kolnai, no "desprezo de si mesmo", onde o processo de divisão e referência intencional do eu para com si mesmo se dá entre "um eu ideal ou formal e um eu material ou essencial” (Kolnai, 2013, p. 42). 
Da mesma forma, a dupla intencionalidade também está presente no caso “angústia 'imotivada”, isto é, sem objetividade clara e que flutua livremente. Neste tipo de estado afetivo, destaca Kolnai (2013, p. 43), “a referência ou retroversão ao próprio eu está psiquicamente reforçada, potencializada”, expressa um papel mais dominante na consciência atual, pois "o que ameaça, o estranho [o alheio], é vivido tanto mais profundamente, quanto mais é 'desconhecido', não indentificável, unicamente presumido ou suspeitado”. Contudo, reforçando sua posição a respeito do caráter essencialmente intencional da angústia, nos diz que, "indubitavelmente, a intenção pode dirigir-se até algo indeterminável - se bem somente em raríssimos casos completamente indefinido".

Ainda sobre a intenção da angústia, explicita Kolnai (2013, p. 43-44) que esta se caracteriza pelo teor abstrato de seu objeto, isto é, pelo sentido de certa indiferença à natureza intrínseca do objeto, a sua essência: "o perigoso se pensa então somente como 'perigo' em geral, e a própria pessoa somente como 'unidade de existência”". Com isso, o autor pretende indicar que "a angústia nunca destaca, em primeiro lugar, certo círculo de interesses da própria pessoa”, pois “o que está em questão é a totalidade, ou, melhor dito, a existência do eu”, invariavelmente, independente de qual dimensão da vida total da pessoa esteja ameaçada, seja sua sobrevivência física, seus meios de sua subsistência, sua posição social, sua liberdade etc. Sendo assim, mesmo em casos em que a angústia se mostra mais fraca, "como consequência da distância ou da eficácia improvável do agente que a produz (...), sua referência está sempre, de algum modo, dirigida aos últimos e grandes interesses vitais" que aparecem como ameaçados. Entretanto, por mais que o giro intencional que a angústia promove em direção ao próprio sujeito seja a sua marca essencial, Kolnai nos alerta que "nunca lhe falta, mesmo assim, certa apreensão intuitiva do objeto" e ainda: "o que produz a angústia não são as situações em si - ainda que possam ser algo misterioso, insuportável, aflitivo -, senão objetos, imagens, estados, acontecimentos, em sua relação objetiva com o sujeito". Conclui, assim, denotando, mais uma vez, a excepcional possibilidade de suprimir a "descarga atual da angústia" a partir do "conhecimento da situação".

Concluída esta passagem do texto destinada à caracterização fenomenológica da angústia, Kolnai (2013, p. 44) passa a analisar o modo intencional do asco tomando em consideração para isso a sua distinção com a angústia e outros afetos análogos. Dessa forma, descreve com relação à intencionalidade do asco uma direção distinta: enquanto na angústia, como vimos, encontramos uma intenção que está duplamente dirigida, simultaneamente, para o objeto que a produz e para sujeito que sofre a ação do objeto, no asco temos uma direção que está marcadamente "dirigida para fora", determinando uma adesão ao objeto que o suscita. Quanto a isso, denota também que "apesar do efeito fisiológico, fortemente acusado, do asco, se desvanece a potente e profunda corrente regressiva da intenção até o sujeito, que temos observado na angústia”. No asco, em relação ao seu objeto "ou também ao modo como objeto se dá e oferece”, não temos essencialmente uma relação objetiva com a própria existência do sujeito, como temos na angústia; diferentemente, o essencial no objeto do asco é a sua constituição mesma ou, melhor dito, sua maneira de ser (Sosein). Com o propósito de explicar esta distinção, descreve:

Para compreender inteiramente esta diferença, representemo-nos o curso típico de um estado de angústia e de um estado de asco. No primeiro caso, o objeto, uma vez "visto", permanece intencionalmente igual, e o sentimento se alça, cresce e aprofunda no próprio eu, seus estados, sua futura sorte: o objeto ameaçador forma o fundo constante, e a própria pessoa a agitada cena da intencionalidade. No caso do asco, ocorre inversamente: enquanto existe, real ou intencionalmente, o estremecimento, a aversão, a gana de vomitar, intensifique-se ou debilite-se a presença do objeto asqueroso, ainda assim, a ponta da intenção se crava no objeto, por assim dizer, o analisa, se mete em seu movimento e duração, apesar de que contra isso se produz uma rebelião que, às vezes, pode levar ao rompimento brusco do contato e a desaparição do asco. (Kolnai, 2013, p. 44-45)

Assim, por este seu momento analítico, Kolnai (2013) descreve que "possui o asco uma função cognoscitiva", isto é, carrega em si a capacidade de "proporcionar imediatamente um conhecimento parcial de seu objeto, que inclusive pode ser uma intuição exata” (p. 45), de modo que "apreende o objeto de modo mais minucioso e pleno" (p. 44) do que a angústia, que pode conduzir só posteriormente ao conhecimento do objeto. Ademais, se refere ao sentido mais unitário de sua intencionalidade, como já vimos, onde não existem dois polos, como na angústia, mas apenas um: o do próprio "objeto em sua plenitude sensível”, que, ao ser referido pela intenção (aguda, por assim dizer) do asco, "pertence ao contorno do sujeito que se pressupõe ao fundo" (p. 45).

Encontramos assim o problema da "proximidade do objeto", motivo este que ocupa um lugar central no asco, segundo Kolnai (2013, p. 45-46, grifos do autor): "a proximidade não é somente motivo ou ocasião para o asco, senão por sua vez um co-objeto do sentimento de asco. Constitui, como relação, a ponte entre a coisa que excita o asco e a pessoa-sujeito que o experimenta”. Reforçando também a ideia da proximidade presente no objeto asqueroso, destaca que "até as sensações de asco imaginárias ou sem causa objetiva - sejam devidas à obsessão, sejam provocadas voluntariamente - situam [e] supõem o objeto asqueroso imaginário, até onde seja possível, muito nas proximidades do sujeito, na esfera mais imediata de seus sentidos". Destaca-se, com isso, mais uma vez, a 
constituição mais intimamente ligada do asco aos conteúdos sensíveis da situação objetiva ao qual se dirige. Também relacionado à questão da pertença do objeto ao contorno do sujeito, descreve o autor:

(...) o sentimento de asco, ao contrário da angústia, é um sentimento periférico, isto é, que se refere à pessoa do sujeito, por assim dizer, em sua superfície, em seu tegumento, em seu sensório, de outra forma - talvez como intenção secundária - ao trato digestivo superior, cum grano salis, ao coração, mas não à existência, ao estado total da pessoa. O estrato mais exterior da pessoa-sujeito e o objeto asqueroso se mesclam assim, pois, "harmonicamente", seja dito no mal sentido. (Kolnai, 2013, p. 46)

Ainda, em relação à proximidade do objeto asqueroso, descreve Kolnai que, além de determinar, “em grande medida, sua ação (...), ademais, entra no caráter asqueroso do objeto - ainda que nunca somente - como uma tendência a estar próximo, a querer acercar-se, pegar-se, não separar-se (...), como um oferecer-se descarada e desenvoltadamente”. Em continuação, descreve, a partir de uma metáfora antropomórfica acerca da maneira própria de afetar-nos do asqueroso, que este "nos sorri sarcásticamente, nos olha fixadamente" (Kolnai, 2013, p. 46), como se falasse maldades e ofensas contra nós.

De maneira mais restrita do que o ódio, compara Kolnai (2013, p. 47), “o asco se produz, geralmente, como uma única reação possível que o objeto provoca de modo imediato", sendo o objeto asqueroso "provocativo" e se manifesta como mais próximo de nós do que o odioso. Sendo assim, pelo caráter de provocação que contém, manifesta o objeto do asco "uma intenção dirigida ao sujeito afetado, como se se preocupasse dele" (Kolnai, 2013, p. 47), mas, alerta o autor, de modo distinto daquela da perseguição ou ameaça por parte do objeto da angústia, que é, como vimos, a sua motivação básica.

Kolnai (2013, p. 47) ao tomar em consideração o "modo como se aproxima de nós 'o asqueroso”, descreve aquilo que nomeou como "o paradoxo do asco" que consiste em ser um sentimento de defesa do sujeito "a algo que lhe afeta univocamente, e que, por assim dizer, tem uma tendência até ele, escruta [e] investiga o objeto em toda sua essencialidade, em lugar de desdobrar-se até o estado da pessoa da pessoa do sujeito". Assim, este paradoxo do asco consiste em possuir uma tendência de se embrenhar, de se ligar intimamente ao mesmo objeto que, teleologicamente, enquanto sentimento de defesa, tende a buscar um afastamento.

O asco, tal como considera Kolnai (2013, p. 47), se situa em uma posição intermediária entre a angústia e o ódio, considerando que a angústia "tende a soltar-se e desprender-se do objeto que lhe provoca” e que o ódio constitui um querer "aniquilar seu objeto ou, ao menos, debilitá-lo ou transformá-lo em um sentido parecido ao aniquilamento”, que, como o asco, também "contém uma tendência espontânea (...) a seguir e escrutar seu objeto". Ainda, em distinção com a angústia, em que "o objeto que a provoca aparece ante ao sujeito como algo ameaçador, 'mais forte do que eu mesmo' - ainda que no caso de crer-me capaz de rechaçar o ataque e inclusive vencer o agressor", declara, "o asco contém certa intenção depreciativa para o objeto, um sentimento de superioridade sobre este”.

Desta forma, descreve o objeto apreendido pelo asco é algo que, essencialmente, não ameaça, mas perturba, "se bem que uma simples perturbação por si mesma não produz asco por muito que se intensifique”. Por esse motivo, "sempre temos por asquerosas coisas que não consideramos plenas e importantes, coisas que não há necessidade de destruir, nem das quais se foge, senão que, mais bem, apartamos simplesmente de nosso caminho". Ainda, dito de outro modo, "enquanto a angústia me obriga a retirar-me e fugir do que me circunda, de minha situação atual, o asco me leva simplesmente a limpar ou escardear meu ambiente, meus arredores”. Com isso, temos também que, este movimento de retirar do espaço circundante aquilo que afeta como asqueroso "implica já um voltar-se até fora, um ocupar-se do objeto, colhe-lo" (Kolnai, 2013, p. 48).

Também associado ao caráter paradoxal da intenção do asco, descreve Kolnai (2013, p. 48), a respeito do "matiz de desafio ou provocação, latente no asco", que este carrega também, "como elemento parcial algo semelhante ao convite, à insinuação, poderia-se dizer como uma isca” ou ainda como uma espécie de incitação sarcástica do nosso apetite pelo objeto. Sobre este momento de sua análise descritiva, afirma também que poderia parecer que nos removemos ao modo fenomenológico de investigação e passado ao psicanalítico. Entretanto, considera que ainda temos nos conservado "dentro da esfera fenomenológica", porque se pode confirmar claramente "que é peculiar do asco um afastamento, não somente do objeto asqueroso, senão de uma suposta atração do sujeito pelo objeto". Sobre isso, apresenta que:

(...) assim como o desejo de fugir, no medo, pressupõe a possibilidade evidentemente que o objeto temido possa chegar perto de mim ou alcançar-me com seu efeito e lastimar-me, assim a gana de vomitar pressupõe também a possibilidade de que o objeto asqueroso chegue, de algum modo, ao meu estômago, sobretudo a minha boca e assim o estremecimento do asco - que aparentemente está menos condicionado fisiológica e corporalmente e por isso é mais intencional que o estremecimento da angústia - pressupõe um possível contato, uma aproximação que não seria devida ao objeto asqueroso aproximando-se, senão a mim mesmo ao sentir certa atração até ele. (Kolnai, 2013, p. 49)

Assim, pode-se notar no asco que "em sua lógica interna está contida a possibilidade de uma apreensão positiva do 
objeto - seja apalpar-lhe ou consumir-lhe ou colher-lhe", de modo que se poderia falar "nos termos psicanalíticos: o asco é mais originariamente ambivalente que a angústia”, pois pressupõe por definição algo como "a fruição, reprimida, do objeto que o provoca". Todavia, não se pretende indicar que "o asco seja, em absoluto, expressão ou consequência dessa repressão ou nada mais que aquele prazer mesmo", mas apenas que essa ambivalência caracteriza uma de suas facetas. Por fim, cabe notar que essa mesma ambiguidade, "ajuda a explicar a peculiaridade do asco, que é produzido pelo objeto como defesa contra ele e, sem embargo, se dirige intencionalmente ao ser do objeto asqueroso e não a própria existência e 'salvação' do sujeito" (Kolnai, 2013, p. 50, grifos do autor).

Com isso, resulta clara a diferença de que, enquanto a angústia contém uma intenção preponderantemente dirigida a existência do sujeito, que "enche, invade incomparavelmente mais a pessoa, se apodera mais do estado total da alma que o asco", no asco se observa como o primariamente determinante "o inteiro conteúdo de ser do objeto", ou ainda, a maneira de ser do objeto, sua constituição mesma, "condicionada pelo fator existencial da proximidade, da periferia do sujeito dado" e que "se relaciona com uma 'seção' qualquer da existência”, possuindo, por outro lado, um fundo existencial mais impreciso, "pois 'perturbação' supõe referência à própria existência, se bem no asco não é primária e determinante”, nem dirigida a sua totalidade, como na angústia. Assim, embora ambos tenham seu foco em um objeto exterior, apenas o asco "se detém nele, se ocupa dele e de sua essência", enquanto a angústia primordialmente "se ocupa da existência do sujeito sob a ação do objeto perigoso". Por essa característica, o asco também se parece com o ódio "em sua tendência a penetrar e internar-se no objeto" (Kolnai, 2013, p. 51-53).

Analisando a relativa demora em decidir-se entre uma tomada de posição positiva ou negativa a respeito de seu objeto, em função dessa latente ambivalência relativa ao objeto asqueroso, considera Kolnai que isso se encontra em dependência "de que o núcleo central do sentimento de asco está constituído pela percepção e a vivência da maneira de ser do objeto", que configura um "sentir-se atraído, apesar de tudo, pelo objeto", por onde "se insinua uma sombra de intenção de reunir-se com ele", mas que o sujeito asqueado também sente, simultânea e consequentemente, como repulsivo, isto é, como algo que tende a querer afastar de seu ambiente imediato. De modo distinto, na angústia se observa algo que "parte da inquietude pela própria existência, a respeito da qual o ser estranho se anuncia e manifesta, imediatamente, já in statu nascendi como algo ameaçador que devemos evitar" (Kolnai, 2013, p. 52-53).

Assim sendo, Kolnai critica a concepção que considera o asco seria uma simples variante da angústia, que denota: "ante o asqueroso experimentamos angústia, só que uma angústia a que se acrescenta uma qualidade especial” (Kolnai, 2013, p. 53). Na continuidade, afirma o autor que, precisamente, "muitos objetos asquerosos são daninhos ou perigosos, sem conter, contudo, esse gesto franco e aberto de ameaça, próprio dos objetos 'temíveis' em sentido estrito", sendo que "temível" seria a propriedade objetiva essencial e intrínseca da angústia, segundo sua compreensão. Dessa forma, especifica que existe uma "entonação sentimental" bastante notável na angústia que se expressa "ante aos perigos ocultos, furtivos, imprecisos, que não se assemelha em nada ao asco" e também que, inversamente, "a produção do asco exige fatores muito distintos que o de uma ameaça pérfida, a qual pode faltar completamente na presença do objeto asqueroso" (Kolnai, 2013, p. 53).

Kolnai explicita também que o objeto asqueroso guarda em seu modo de aparecer "tanto um declive até o recôndito, oculto, dissimulado, impenetrável e suspeito como o descaramento, a importunidade, a intrusão, a incitação ou tentação", "ao mesmo tempo algo chocante e misterioso" (Kolnai, 2013, p. 53). Em seguida, destaca que o asco se mostra como perturbação derivada da "proximidade forçada que brota da maneira de ser do objeto", carregando, "ao mesmo tempo, um matiz secundário de reserva, de espreita" em relação ao objeto e, com isso, por este "matiz defensivo", fica expresso seu modo específico de referência à existência, "acaso não muito vaga e geral”, tendo em vista que não está em absoluto isento de uma preocupação com a própria existência (Kolnai, 2013, p. 53-54). Contudo, importa precisar "somente que esta referência intencional à existência não se dirige à situação própria (ao estado próprio!), sob a eficácia do objeto, senão à proximidade do objeto, tomada no sentido de perceptibilidade sensível, 'palpabilidade', possibilidade de uma relação funcional, intimidade e comunidade" (Kolnai, 2013, p. 89-90).

\subsection{Os tipos de asquerosidade e a relação do asco com os sentidos, a vida e a morte}

Na terceira seção de seu ensaio denominada "O asqueroso”, Kolnai (2013) dirige sua atenção mais uma vez à qualidade objetiva constituída pelo asco, dessa vez passando pela explicitação de sua relação com os sentidos, passando também por uma extensa descrição dos principais tipos experienciais de objetividades asquerosas ${ }^{1}$ na esfera física e moral tal como opera em sua delimitação. Por fim, apresenta sua análise reflexiva a respeito da relação do asco com a vida e a morte.

\footnotetext{
Em função do nosso objetivo meramente reconstitutivo, citaremos apenas um exemplo de cada esfera de asquerosidade, física e moral. Não contemplamos neste trabalho todas as análises particulares dos objetos típicos citados pelo autor em função de sua quantidade e detalhamento que escapa à dimensão circunscrita de nossa exposição, porém convidamos o leitor após essa introdução a entrar em contato com a sua obra para constatar e resgatar, em toda sua riqueza e rigor, as suas análises sobre a variadade de objetos asquerosos.
} 
Tomando em consideração a relação do asco com os sentidos da esfera perceptiva (ou sentidos sensoriais ${ }^{2}$ ), denotando sua característica fundamentalmente estética, Kolnai destaca que "os principais condutores da sensação do asco são o olfato, o tato e a visão”. Esclarece, de modo geral, a sua concepção de que o paladar é redutível ao olfato, "sempre que se prescinda dos quatro sabores fundamentais” (a saber, azedo, amargo, doce e salgado). Com isso, explicita que "não existe [...] sabor asqueroso que não seja redutível claramente ao correspondente odor asqueroso, se bem não pode negar-se que o matiz amargo, adocicado, azedo do objeto especializam algo mais a sensação de asco correspondente” (Kolnai, 2013, p. 54). Dessa forma, expõe que os sentidos sensoriais do olfato e paladar

(...) estão unidos muito intimamente e - deixando de lado as razões fisiológicas - o sabor se reduz mais ao odor do que o inverso, porque o olfato - puramente empírico - abarca uma classe de objetos muito mais ampla e em geral merece com mais razão o nome de "sentido", em sua acepção estrita, porque desempenha melhor a função de descobrir objetos. (Kolnai, 2013, p. 54-55)

Assim sendo, antes de adentrar a especificidade de cada um dos sentidos sensoriais apresentados como principais condutores do asco, considera brevemente a "relação peculiar entre o asco e o 'doce”" como "um asco de 'ordem superior”, que correspondente ao tipo de asquerosidade moral despertado pela saciedade, pois o asco que pode ser produzido pelo sabor em questão "depende, por completo, das circunstâncias especiais em que se saboreia e dos elementos associados ao sabor". Dessa forma, denota que não é possível dizer, seguindo nossa intuição, que o doce seja asqueroso "por si mesmo" nem que ele "esteja representado em maior medida entre os objetos asquerosos ao paladar que os demais sabores fundamentais", porém concorda, contudo, que "talvez isto poderia dizer-se mais bem do amargo” (Kolnai, 2013, p. 55).

Na continuidade, Kolnai (2013) considera a impossibilidade de representarmos o asco a partir da audição. Segundo sua análise, isto se deve "não somente pela relativa 'incorporeidade’ da audição, senão também, em geral, porque lhe falta referência intencional ao objeto, conexão direta com o objeto". Sendo assim, nos explicita que "os sons e os ruídos unicamente nos 'revelam', nos dão notícia de objetos, mas não nos 'presentam' no mesmo sentido que a visão, o tato e o olfato”, que podem captar e apreender "os objetos materiais por distintos lados e aspectos"

\footnotetext{
O autor não emprega especificamente o adjetivo "sensorial" em sua terminologia a respeito dos sentidos referentes aos modos de sensibilidade da esfera perceptiva. Todavia, tomamos a liberdade de empregar esse adjetivo para evitar as possíveis ambiguidades contidas na palavra "sentido", tomando em consideração a diversidade implícita de sentidos possíveis que a palavra guarda, quando tomada de modo isolado, especialmente quando empregada no contexto da fenomenologia.
}

e, embora todos eles (visão, tato, olfato) apresentem uma limitação insuperável dentro de sua própria esfera perceptiva isolada, todos possuem "uma maior imediatidade que a audição não conhece” (Kolnai, 2013, p. 55). Sendo assim, "a figura, a cor, a superfície e a consistência, o odor e o sabor pertencem muito mais constitutivamente ao objeto percebido que sua 'voz' ou que o ruído que produz", que, consequentemente, "por assim dizer, somente toma do objeto sua 'origem', e forma em seguida um 'ente' peculiar e independente, inclusive um 'mundo' peculiar”. Dessa maneira, o autor declara que, "em geral, o asco não pode ser transmitido pela audição [...] posto que a audição nunca presenta por modo imediato "uma maneira de ser' alheia, nem se aproxima do sujeito”. Por fim, denota que "todo asco auditivo é, em boa parte, asco moral; pressupõe um número suficiente de relações associadas ao objeto, que se dão secundária e não imediatamente”, com raras exceções (Kolnai, 2013, p. 55-56).

Com isso, Kolnai (2013) adentra na descrição dos principais sentidos sensoriais que formam suportes do asco, embora não tenham todos a mesma força de suscitação. Inicialmente, apresenta o olfato - "compreendendo nele também o paladar, em parte como reforço, em parte como estreitamento" - como "o verdadeiro assentamento do asco", visto que ambos afetam "o trato digestivo superior de maneira imediatíssima”, suscitando com maior facilidade a "gana de vomitar" ou a "náusea do asco" (“a qual, por sua vez, alude à intenção de comer”, o que dimensiona a característica de ambivalência do objeto asqueroso). Igualmente, denota que "os tipos asquerosos de odor são dados mais primários e intensos que quaisquer das outras formas do asqueroso e necessitam muito menos o complemento de ideias ou percepções associadas”. Dessa maneira, temos no sentido do olfato uma efetivação completa da dimensão exigida da proximidade, devido ao "caráter íntimo desta modalidade sensível”, o que justifica a "sua importância primária para o asco" (p. 57).

Kolnai (2013) posiciona o tato em segundo lugar na correspondente hierarquia dos sentidos sensoriais em sua vinculação com o asco. Destaca, comparativamente, que o tato é "também mais íntimo do que a visão e em certo sentido - ainda que não sugere nunca uma proximidade tão íntima - acentua mais o fator de proximidade que o próprio olfato”. Em relação a isso, expõe essa semelhança do tato apontando para o "fator de contato, nessa tendência a apertar-se” que guarda a intenção do asqueroso, distinguindo-o (p. 58). Do mesmo modo, podemos dizer que mesmo a dimensão da proximidade de, maneira muito intrínseca em seus graus de apresentação, implica de maneira importante o tato, pois o que toca e se adere na periferia do sujeito se explicita primariamente a partir desse sentido mesmo. Kolnai (2013, p. 57-58) ressalta ainda que na esfera do tato não se dão aquelas entonações, por assim dizer, tão cruas, intensas e inequívocas como as "que existem nos odores". Ainda assim, expõe a possibilidade de "sentir asco, por regra geral, ao receber 
a impressão tátil do flácido, mucilaginoso, pastoso e, em certo sentido, do mole em geral", assim como o pegajoso, tíbio, viscoso, ceroso. Apesar disso, ainda explica que tais qualidades sensíveis do tato não são por si mesmas asquerosas, "senão que estão melhor 'predispostas' que outras para realizar valores asquerosos", denotando, com isso, que no asco tátil, mais do que as sensações em si, se faz necessária a intervenção de outros elementos adicionais determinantes.

Para ilustrar isso, o autor destaca o "podre" que para ele parece ser "o protótipo do asqueroso”. Então, convoca-nos a pensar "no asco que sentimos ao tocar (eliminado o odor) pus, supurações, carne fétida e decomposta” e, expõe que há um odor muito próprio, específico e pesado correspondente à putrefação, mas no que diz respeito ao tato, "o asco se produz por virtude de certas propriedades táteis de consistência, intermediárias, se bem que muito características". Enfim, remetendo ao "fator de contato" presente no asco tátil, destaca "outra forma principal de união íntima, que ocupa o segundo lugar ao lado da recepção de alimentos": "a esfera da sexualidade, que também proporciona um grande número de motivos de asco", apesar de que sua relação com este seja considerada "mais frouxa, ou, pelo menos, menos típica e exemplar" que a esfera dos alimentos. De toda forma, descreve "o motivo do "íntimo contato com uma matéria viva estranha”" como central na sexualidade, sendo, também por isso, uma esfera potencialmente suscitadora do asco (Kolnai, 2013, p. 58).

Por fim, a respeito da relação dos sentidos sensoriais com o asco, expõe Kolnai (2013) o lugar da visão, considerando que esta "nos presenta o objeto de um modo distinto do tato e do olfato", pois o sentido visual "é capaz de nos fornecer uma imagem do objeto mais variada, mais ampla e mais 'adequada' - 'ver' algo quer dizer 'conhecê-lo' em um sentido muito distinto que 'cheirar' ou 'tocar algo'”. Contudo, estabelece a distinção a respeito da "impressão visual” declarando que ela não é capaz de nos conduzir como o tato e o olfato "a uma região essencial do objeto”. Em semelhança à "relação estreita entre o ver e o conhecer discursivamente", destaca Kolnai que se pode constatar uma relação "entre o cheirar ou apalpar e esse advertir, perceber, 'sentir', que pode ser surdo, unilateral, 'irresponsável' frente ao objeto, mas que, apesar disso, pode penetrar muito profundamente no objeto" (p. 58-59).

Neste sentido específico, na análise de Kolnai, o tato se aproxima mais da visão do que o olfato, porque explica que "a sensação visual nos procura o objeto somente - ou, pelo menos, conforme a sua função mais sobressalente - em sua estrutura e forma, com suas cores, linhas, perspectivas, ou, pelo menos, algumas delas”. Ainda, observa que há "uma verdadeira qualidade total e, portanto, um autêntico asco visual”, como se pode constatar nas “cores e, em geral, ‘qualidades visíveis’ próprias da putrefação", também no caso da "impressão visual do 'fervilhar' e 'pulular”' (tipicamente atrelado à germinação de insetos na matéria viva em decomposição), mas que não se dão da mesma forma "tão acusada e inequívoca" como os odores e, inclusive, nas sensações táteis suscitadoras de asco (Kolnai, 2013, p. 59-60).

Deste modo, no asco visual, os elementos associados ao conjunto total do objeto visto, os aspectos contextuais e, inclusive, aqueles ligados ao pensamento, tem uma participação muito maior na sua determinação, dependendo assim de modo primordial "da constituição mais prolixa" e particular de seu objeto, do que o asco tátil e olfativo. Reconhece ainda que "a visão fornece uma compreensão de tal sorte ampla do objeto que, apesar da falta de 'intimidade imediata' nela, todavia é capaz de transmitir uma qualidade autêntica, sui generis, do asco", que "alude à qualidade olfativa do asqueroso, mais imediata e primigênea” (Kolnai, 2013, p. 60).

Seguindo sua análise, adentra Kolnai (2013, p. 60) em um exame dos objetos típicos do asco físico, isto é, aquele tipo de asco "produzido, principalmente, por impressões sensíveis", descritos "sobre a base de um método de divisão puramente empírica”, a saber: a putrefação, os excrementos, as secreções corporais, a sujeira, certos animais (os insetos, principalmente), certos alimentos, o corpo humano (em função de sua proximidade - real ou aludida -, deformação, enfermidade ou ainda por uma aproximação sexual indesejada), e também certo tipo relacionado à chamada "fecundidade excessiva".

Destes objetos fisicamente asquerosos, analisados por Kolnai (2013, p. 60-61), destacamos a putrefação, em que "estão incluídos: a decomposição de um corpo vivente, a corrupção, a desintegração, o odor cadavérico, e, em geral, o trânsito da matéria viva ao estado de matéria morta". Com isso, explicita que "não é este último estado o que propriamente produz o asco”, pois "o inorgânico, com efeito, não produz asco" (com exceção da sujeira, como dito). Assim sendo, "a nota de asquerosidade reside especialmente no processo da putrefação e na coisa que a sofre”, de modo que "o morto, quando se presente simplesmente como algo vivo que tem deixado de funcionar, nunca é asqueroso", pois "é necessária, para produzir asco, uma dissolução substancial, um processo duradouro, ao menos intencionalmente, que, por assim dizer, deve ser, por sua vez, uma 'manifestação de vida”". Dessa forma, explicita "a relação do asco com o vital positivamente, com o animado", dado que "indubitavelmente, à dissolução da vida, que há na putrefação, está associado também um certo - muito notável - aumento de vida, uma patentização acusada de que algo vivente 'existe ali”.

Ao analisar o asco moral, Kolnai (2013) explica que pelo termo "moral" não compreende, rigorosamente, o mesmo que "ético", "senão algo assim como 'espiritual' - desde logo, também mais ou menos referido ao ético -, em oposição ao "físico". Dessa maneira, parte em uma tentativa de classificar "os matizes objetivos do asco" da esfera moral, embora considere que não poder aspirar a 
mesma evidência e clara delimitação que aquela observada na classificação dos objetos fiscamente asquerosos. Sendo assim, entre os típicos objetos moralmente asquerosos, destaca: a "uniformidade pesada" (característica do asco por saciedade), a "vitalidade exagerada ou que se desenrola em lugar inadequado" (como a "sexualidade desordenada", a intelectualidade ou hiperrefinamento estéreo, extravagante, fora de lugar e/ou sem finalidade), a mentira (e, ainda, a mendacidade, falsidade, infidelidade, traição etc.) e a "moleza” moral (p. 72-81).

Em relação ao asqueroso moral, destacamos o exemplo da "sensação de desagrado produzida por uma uniformidade pesada” (Kolnai, 2013, p. 72) - ou ainda, como traduzido na edição inglesa, pela "monotonia fatigante" (tiresome monotony) (Kolnai, 2004, p. 63) - a qual "pode adquirir um matiz parecido ao asco”, que se manifesta "quando aquela vivência constante é prazerosa, originariamente ou por si”, de modo que não o objeto, mas o prazer mesmo, pelo "fenômeno de sua persistência indefinida”, se faz asqueroso e suscita no eu uma reação de defesa correlativa. Desse modo, o autor denota que o asco é responsável por impedir um "afogar-se em um prazer”, não no sentido de que "este prazer deixe-se de sê-lo", mas apenas que este "se faz unicamente insosso, confuso, e se põe em oposição, de alguma modo sensível, à vontade vital da personalidade" (Kolnai, 2004, p. 63).

Assim sendo, esse tipo de asco por saciedade pode aparecer em todo prazer “que é bastante ‘concentrado’ para destacar-se do resto da vida como um prazer especial continuado", em "toda permanência em um prazer que se tem feito sem finalidade”. Pode-se observar no caso de estados de embriaguez (não necessariamente alcoólica), de "inatividade duradoura, ainda que combinada de saúde e com bem estar", pela contínua consumação de alimentos doces, prazerosos etc. Dessa forma, neste tipo de asco moral se expressa então uma "vitalidade unilateralmente exagerada, que se move indefinidamente, por assim dizer, em recinto limitado", também presente em outros tipos de asco físico e moral (Kolnai, 2013, p. 72-73)

Por fim, analisa Kolnai (2013) a relação do asco com a vida e a morte. Na medida em que "o asco se produz pela proximidade, melhor dito, pela ação provocativa que palpita nesta proximidade - de substâncias que, por sua maneira de ser, aludem, de certo modo, à 'vida' e à 'morte”, questiona a respeito da noção de "excesso de vida" contida em todo objeto asqueroso, que explicita nele um "sublinhamento, patentização exagerada, sobreacentuação, redundância inchada de vitalidade e organicidade, como antínteses de norma, direção, plano de vida”. Para isso, ressalta "a contraposição entre a 'agitação vital reduntande' e a vida organizada, sujeita a fins”, sendo o primeiro caso, enquanto "exuberância de vida", o tipo que se manifesta no objeto asqueroso. Trata-se de uma exuberância de um tipo de vida inferior, tendente à forma da "liquefação", do "derretimento", em "antíntese à delimitação e individualidade”, que caracterizaria ao tipo de vida superior, segundo o autor, ligada à dimensão do espírito: a vida controlada, delimitada, individuada. Com isso, denota que "a vida inferior é mais propensa à proliferação ilimitada, irreprimível, que para nada tem em conta a qualidade", por isso "é, de certo modo, vida mais desnuda; é mais mero-viver”, no sentido de que mostra uma "hipertrofia desordenada, por assim dizer pretenciosa”, com intenção de ser indefinida. Como ilustração nos oferece a mescla indiferenciada, que "nos suscita a imagem da putrefação com sua tendência a extender-se indefinidamente e a homogeneizar o todo", também "a umidade, a pastosidade e pegajosidade que são elementos do asco" (p. 83-84).

Kolnai (2013, p. 84-85) descreve que o sentido desta vitalidade exagerada remete ao movimento de "borrar os limites e penetrar todo o que rodeia, em completa contraposição com a forma e o isolamento que caracterizam o indivíduo", voltado à homogeneidade e comunidade no sentido "de um derreter-se, de um liquefazer-se - total e parcialmente (...) - de cada ser". Por conseguinte, remete "à confusão, à bagunça e, definitivamente, à decomposição, pulverização, indiferenciação e equiparação universal". Dessa forma, de modo paradoxal, com sua vitalidade exagerada, "o que se nos anuncia no fenômeno da asquerosidade é, se nos atermos a sua completa intenção, morte e não vida", pois "nesse sobrante de vida reside a não-vida, a morte”. Por isso, ao analisar a referência intencional do asco, elucida que há morte

(...) no interior de sua referência intencional à vida mesma, como se o sobrante de vida que nele se manifesta passasse rapidamente, por assim dizer, ao modo de curto-circuito, à morte, como se a vida potenciada e condensada nascesse de um desejo impaciente até a morte, de um afã de gastar e esbanjar da energia vital, de um prazer macabro de libertinagem da matéria. (Kolnai, 2013, p. 85)

Por esse motivo, de acordo com Kolnai (2013) o "excesso de vida" contido no asco corresponde sempre a "uma vida empobrecida em suas dimensões, apesar da nota de 'abundância' exagerada, um abandono da estrutura total da vida, um transbordar ao largo de uma só linha de vida”, de modo que o pano de fundo intencional, as perspectivas contextuais, o caráter de integração e totalidade lhe faltam: "a vida é condensada em um 'fluido' da vida", por essência homogêneo. Dessa forma, se mostra por meio do objeto asqueroso uma "morte que se produz paradoxalmente pelo caminho da acumulação da vida”, como um tipo especial de zombaria ou distorção latente, "frente ao simples morrer e fenecer”. Indica o filósofo ainda que "prenhe de morte" [...] "o objeto asqueroso se encaminha, com passos visíveis, até sua própria desintegração, seja na forma de decomposição pútrida, desorganização, dissipação, captura por forças vitais mais grosseiras, mais inferiores” (p. 85-86). Ainda, em função dessa síntese 
paradoxal da vitalidade conjurada no marco da morte, o objeto asqueroso também pode suscitar um tipo peculiar de fascinação ou interesse, o que acontece em muitos casos, segundo o autor.

Aponta Kolnai (2013, p. 87) também outra referência intencional ligada à morte que se "mostra adequada e conveniente à existência": o caráter de nocividade ou agressividade dos objetos asquerosos. Ou ainda, sua ameaça de contagiar a tudo o que tocam com a decomposição. Todavia, alerta que essa ameaça de propagação da decomposição presente no asqueroso se dá de um modo singular como numa relação de comércio ou tráfico com o sujeito afetado. Ainda assim, contudo, retoma que o essencial na referência intencional do asco é a própria maneira de ser do objeto, "inclusive a sua expansividade e agressividade, mas não o perigo que dele emana", de forma que a ação temida do asqueroso se mostra mais

(...) como algo somente periférico "molesto" que como algo mortal que penetra a vida. Se teme sujar-se com o objeto e que se nos pegue; tememos inclusive entrar com ele em certa comunidade, em uma relação duradoura que se marque e que prejudique a própria pessoa; mas não morrer, a ver-nos gravemente "danificados". (...). No asco não se pensa nas "consequências" de um contato mais íntimo, senão no reforçamento, que então se apresenta, da relação de proximidade, a intensificação "ameaçadora" do asco mesmo por virtude da submersão no objeto. (...). A relação intencional à morte (...) não relaciona ao asqueado com seu morrer ou com seu estado depois da morte, ou com seu morrer espiritual-moral, senão (...) com seu estar posto dentro de algo morto e cheio de morte. (Kolnai, 2013, p. 87)

Assim, finaliza Kolnai (2013) sua exposição sobre a relação do asco com a vida e a morte apresentando essa dimensão a partir das características já mencionadas da provocação e da proximidade. Dessa forma, diz que a provocação do asqueroso se apresenta de tal modo que o objeto manifesta para o sujeito ao mesmo tempo a vida e a morte e ainda aproxima ambas a ele. Também denota que a proximidade do objeto asqueroso "forma uma unidade com a referência intencional à vida e à morte, com a constituição do objeto mesmo, com sua manifestação de vida e morte", de modo que no próprio objeto "existe uma proximidade 'perversa", em que se mostra, "ao mesmo tempo, calor sufocante de vida e negação das tensões que constituem a vida; uma proximidade que, por virtude de sua natureza intrínseca, tende a estender-se, a inchar-se e engrossar ao modo de uma avalanche", e, desse modo, a mostrar-se de forma "acentuada, agressiva, 'quente', aderente” (p. 90-91). Também, elucida que a possibilidade de "ser estimulado e sua negação interior", que caracteriza a provocação mesma do objeto asqueroso - que se nos expressa pela tentação de realizar uma relação funcional com o objeto, como comer, apalpar, etc. (vida), enquanto, ao mesmo tempo, nos fere e ameaça (morte) por meio da íntima relação (negativa) com seu modo de ser essencial -, esta baseada em um tipo de “'afinidade' do sujeito com aquela vida que é ao modo de morte" (p. 88). Por fim, sobre esta afinidade, de modo um tanto poético, indica:

A careta de morte que há no asqueroso nos adverte nossa própria afinidade com a morte, nossa sujeição à morte, nosso secreto prazer de morte; mas não por isso o adverte como a caveira e o relógio de areia indicam a inexorabilidade da morte, que se aproxima sem compaixão, como a hora da decapitação a um condenado, senão que indica nossa servidão essencial à morte, o sentido de morte de nossa vida, nossa consistência em matéria sacrificada à morte; se poderia dizer, ébria de morte e disposta à putrefação. $\mathrm{O}$ asqueroso não nos põe nenhum relógio de areia diante dos olhos, senão um espelho côncavo; nem a caveira em sua mondada eternidade, senão justamente o que já não há na caveira, a putrefação jorrante. (Kolnai, 2013, p. 89)

\section{Considerações finais}

Com essa breve reconstituição dos conteúdos expositivos presentes no ensaio de Aurel Kolnai sobre o fenômeno do asco, podemos entrever, ainda que de maneira concisa, algo do rigor, da riqueza, da minúcia e da profundidade oriunda do trabalho descritivo-analítico da fenomenologia dedicado a elucidar a esfera afetiva que está entre as estruturas de sentido da vida de consciência mais difíceis de aclarar a partir de conceitos. Sendo assim, importa-nos destacar como significativo e preocupante o existente esquecimento ou desatenção refente ao trabalho desse autor bem como de outros autores do movimento fenomenológico em sua tematização sobre a vida afetiva. Apontamos, com isso, para a importância e proficuidade do resgate dos trabalhos fenomenológicos clássicos em vista de sua multiplicidade, relevância e validade para o debate contemporâneo a respeito dos afetos e da afetividade em geral.

Destarte, a contribuição de Aurel Kolnai à escola da fenomenologia se faz notar a partir de sua capacidade de promover uma singular compreensão sobre os traços essenciais a partir dos quais se estruturam e organizam algumas de nossas vivências afetivas, explicitando a sútil e intrincada complexidade encontrada em algumas de nossas experiências cotidianas, denotando as vicissitudes que as particularizam e aproximam. Ainda, em função de sua riqueza e abrangência descritiva, consideramos o trabalho fenomenológico de Kolnai como útil e relevante para o cenário de debates fundamentais ligado ao campo psi. Por fim, também destacamos a potencial capacidade de sua obra de nos aproximar, de maneira ativa e 
demonstrativa, do exercício reflexivo da fenomenologia, servindo-nos com isso como suporte esclarecedor de seus alcances metodológico-investigativos no sentido da descrição fenomenológica das vivências afetivas.

\section{Referências}

Calhoun, C. \& Solomon, R. (1996). ¿Qué es una emoción? Lecturas clásicas de psicología filosóficas. México: Fondo de Cultura Económica.

Casanova, M. A. (2010). Compreender Heidegger (2. ed.). Petrópolis: Vozes.

Ferran, I. V. (2013). Introducción. Em Kolnai, A. Asco, soberbia, odio: fenomenología de los sentimientos hostiles (p. 19-32). Madrid: Ediciones Encuentro.

Ferran, I. V. (2015). The emotions in Early Phenomenology. Studia Phaenomenologica, 15, 329-354.

Goto, T. A., Telles, T. C. B. \& Paula, Y. A. (2016). A questão dos afetos na fenomenologia de Edmund Husserl: um estudo preliminar. Revista Pesquisa Qualitativa, 4(4), 34-54.

Kolnai, A. (2004). On Disgust. Chicago: Open Court.

Kolnai, A. (2013). Asco, soberbia, odio: fenomenología de los sentimientos hostiles (Íngrid Vendrell Ferran, Ed. \& Trad.). Madrid: Ediciones Encuentro.

Korsmeyer, C. \& Smith, B. (2004). Visceral Values: Aurel Kolnai on Disgust. Em Kolnai, A. On Disgust (p. 1-25). Chicago: Open Court.

Sartre, J. P. (2008). Esboço para uma teoria das emoções. (Paulo Neves, Trad.). Porto Alegre: L\&PM.

Quepons, I. (2014). Aurel Kolnai, 2013. Asco, soberbia, odio. Fenomenología de los sentimientos hostiles. Madrid Encuentro, 200 p. Traducción de Ingrid Vendrell Ferran. Open Insight, 5(8), 175-184.

Yuri Amaral de Paula - Mestrando em Psicologia na Universidade Federal de Uberlândia (UFU), Uberlândia, Minas Gerais. Graduado em Psicologia pela Universidade Federal do Triângulo Mineiro (UFTM), Uberaba, Minas Gerais. E-mail: yuri.a.p@live.com

Tommy Akira Goto - Doutor em Psicologia pela Pontifícia Católica de Campinas (PUC-Campinas). Professor da Pós-graduação e Graduação de Psicologia da Universidade Federal de Uberlândia (UFU), Uberlândia, Minas Gerais, Brasil. E-mail: prof-tommy@hotmail.com

Recebido em 27.12.2016

Aceito em 28.03.2017 